\title{
MEASUREMENT OF FETAL ABDOMINAL SUBCUTANEOUS TISSUE THICKNESS BY ULTRASOUND IN PREDICTION OF BIRTH WEIGHT AT TERM PREGNANCY
}

\author{
By \\ Yousri A. Oun; Mohamed M. Gebril and Saged M. El-Mazzaly \\ Department of Obstetrics and Gynecology, Faculty of Medicine, Al-Azhar University \\ E-mail: Yousryoon@gmail.com
}

\begin{abstract}
Background: Assessment of fetal weight is a vital and universal part of antenatal care, not only in the management of labor and delivery but often during the management of high risk pregnancies and growth monitoring. The common methods to estimate fetal birth weight are clinical and sonographic estimation with a wide range of accuracy.
\end{abstract}

Objective: To correlate fetal abdominal subcutaneous tissue thickness (FASTT) measured by abdominal ultrasound at term and birth weight measured immediately after delivery and to obtain a cut-off value of FASTT to predict large and small for gestational age babies in our population at Alsayed Galal Hospital and Damanhur medical national institute (D.M.N.I).

Patients and methods: This prospective observational study was carried out at Alsayed Galal Hospital and Damanhur medical national institute (D.M.N.I).A total of 200 pregnant women at term admitted to the labor ward for delivery at Alsayed Galal Hospital and D.M.N.I. between June 2019 and March 2020.

Results: Of the 200 neonates of the included women, 148 (74.0\%) had birth weight (2500-4000) g 14 (7.0\%) had birth weight $<2500 \mathrm{~g}$, while $38(19.0 \%)$ had birth weight $>4000 \mathrm{~g}$. There was a significant positive correlation between fetal anterior abdominal wall fat thickness and birth weight. FAST was a significant predictor of Birth weight $>4000 \mathrm{~g}$, as indicated by the significant large area under the curve (AUC).

Conclusion: FASTT is a good indicator of birth weight. It is a better parameter for LGA than SGA. It showed a high statistically significant correlation with AC. Yet, it is less accurate than AC as an indicator of fetal macrosomia. FASTT is not affected by fetal gender and has no direct relation to the mode of delivery.

FAST can be combined with weight estimation formulas as a method to increase its accuracy especially at birth weight extremities. However, a large study conducted on a wider scale of Egyptian population should be done in attempt to generate formulas for the estimation of fetal weight based on the Egyptian ethnic group and be the reference of medical practice in Egypt.

Keywords: FASTT, Ultrasound, Birth weight term pregnancy, LGA, SGA.

\section{INTRODUCTION}

Birth weight of an infant is the single most important determinant of newborn survival. Both low and excessive fetal weights at delivery are associated with an increased risk of newborn complications during labor and puerperium. Limiting the potential complications associated with the birth of both small and excessively large fetuses requires that accurate estimation of fetal weight occurs before decision to deliver is made (Bajracharya et al., 2013). 
Fetal macrosomia has increased maternal morbidity and mortality such as prolonged labor, increased rates of perineal laceration, postpartum hemorrhage, operative vaginal delivery and cesarean section (Spellacy et al., 2015). It has increased perinatal morbidity and mortality such as shoulder dystocia, fetal distress, birth asphyxia and neonatal death. Newborn weight exceeding $4000 \mathrm{~g}$. is also a frequently used threshold to define macrosomia because there are no methods presently available to estimate excessive fetal size accurately macrosomia cannot be definitively diagnosed until delivery (Cunningham et al., 2014).

The common methods to estimate fetal birth weight are clinical and sonographic estimation with a wide range of accuracy (Kiserud et al., 2017). Several studies have shown that sonographic measurements of fetal abdominal circumference and fetal abdominal subcutaneous tissue thickness are useful for predicting fetal macrosomia (Bhat et al., 2014).

Measurement of fat in the abdominal wall is a simple technique with sensitivity for predicting low birth weight and macrosomia (Larkin et al., 2012). Many studies have demonstrated that expected fetal weight (EFW) by the traditional techniques is not a reliable indicator of growth abnormalities such as macrosomia, consequently several other echo graphic measurements have been proposed (Chen et al., 2014).

Ultrasound has its limitations despite the use of more than 50 different formulae to estimate fetal weight as their performance is poor at the extremes of fetal weight. There has been emerging interest in studying fetal soft tissue measurements to improve the detection of growth abnormalities (Chen et al., 2014).

The aim of the study was to correlate fetal abdominal subcutaneous tissue thickness (FASTT) measured by abdominal ultrasound at term and birth weight measured immediately after delivery and to obtain a cut-off value of FASTT to predict large and small for gestational age babies in our population at Alsayed Galal Hospital and D.M.N.I.

\section{PATIENTS AND METHODS}

This prospective observational study was carried out at Alsayed Galal Hospital and D.M.N.I. A total of 200 pregnant women at term admitted to the labor ward for delivery at Alsayed Galal Hospital and D.M.N.I.

\section{Inclusion Criteria:}

Singleton viable pregnancy, full term pregnant patients with gestational age 3840 weeks (based on first day of last menstrual period of regular menstrual cycles, first trimestric or early second trimestric ultrasound scan) referred to labor ward for delivery either for induction or by cesarean section.

\section{Exclusion criteria:}

Gestational age less than 38 weeks or more than 40 weeks, multiple pregnancies, fetal anomalies, IUFD, diabetes mellitus and hypertension, past history of IUGR or macrosomia.

\section{All included women after informed consents were subjected to:}

1. Full history taking with special emphasis to maternal age, parity, 
maternal weight, gestational age, as well as presence of any disease.

2. Abdominal examination to assess the fundal height and estimated fetal weight.

3. Ultrasound assessment of fetal anatomy and fetal biometry including:

A. Biparietal (BPD) that was measured on a transverse axial section of the fetal head which included the falxcerebri anterior and posterior, the cavum septum pellucidum anteriorly in the midline and the thalami. The BPD was measured from the outer edge of the nearer partial bone to the inner edge of the more distant partial bone.

B. Femur length (FL) was measured with the bone across the beam axis, the strong acoustic shadow behind the femoral shaft and the visualization of both cartilaginous ends indicated that the image plane was on the longest axis and is the optimal measurement plane. The calipers were placed along the diaphyseal shaft excluding the epiphysis.

C. Abdominal circumference (AC) was measured at the level of the liver and stomach including the left portal vein at the umbilical region.

4. Measurement of fetal abdominal subcutaneous thickness by ultrasound:

- Fetal Abdominal Subcutaneous Tissue Thickness (FASTT) was measured at the anterior $1 / 3$ of abdominal circumference between outer and inner edges of abdominal wall by abdominal ultrasound at the level of measurement of abdominal circumference.

- Large for gestational age (LGA) is defined as birth weight >90th percentile in our study population and small for gestational age (SGA) as $<10$ th percentile.

5. The actual birth weight was determined after delivery.

Outcomes: Primary outcome: Accuracy of FASTT in prediction of birth weight.

Secondary outcome: Accuracy in prediction of low birth weight and macrosomia.

\section{Statistical analysis of the data:}

Data were fed to the computer using IBM SPSS software package version 20.0. Qualitative data were described using number and percent. Comparison between different groups regarding categorical variables was tested using Chi-square test. Quantitative data were described using mean and standard deviation for normally distributed data while abnormally distributed data was expressed using median, minimum and maximum. For normally distributed data, comparison between two independent populations was done using independent t-test. Significance test results are quoted as twotailed probabilities. Significance of the obtained results was judged at the $5 \%$ level. 


\section{RESULTS}

There was a significant association between the birth weight category and the level of FAST (Table1).

Table (1): Distribution of the studied group regarding the birth weight group in relation to FAST

\begin{tabular}{|l|c|c|c|c|}
\hline Weight & $\begin{array}{c}\text { Birth Weight } \\
(<\mathbf{2 5 0 0 g}) \\
\text { Parameters }\end{array}$ & $\begin{array}{c}\text { Birth Weight } \\
(\mathbf{2 5 0 0 - 4 0 0 0 g}) \\
(\mathbf{n = 1 4 8})\end{array}$ & $\begin{array}{c}\text { Birth weight } \\
(\mathbf{>} \mathbf{4 0 0 0} \mathbf{g}) \\
(\mathbf{n = 3 8})\end{array}$ & P \\
\hline Birth Weight (g) & & & & \\
Range & $2367.0-2509.0$ & $2510.0-3996.0$ & $3982.0-4448.0$ & 149.44 \\
Mean \pm SD & $2430.0 \pm 46.3$ & $3171.8 \pm 451.8$ & $4239.3 \pm 125.4$ & $0.0001^{*}$ \\
Median & 2400 & 3180 & 4150 & \\
\hline FAST (mm) & $3.60-4.10$ & $4.20-14.80$ & $6.80-14.80$ & 31.113 \\
Range & $3.78 \pm 0.19$ & $9.17 \pm 3.02$ & $11.11 \pm 3.28$ & $0.0001^{*}$ \\
Mean \pm SD & 3.8 & 9.0 & 11.0 & \\
Median & **. Correlation was significant at the 0.01 level (2-tailed).
\end{tabular}

There was a significant positive correlation between FAST and both fetal estimated weight by Hadlock's formula

(g) and actual fetal weight (Table 2, Figure 1).

Table (2): Correlation between FAST and both EFW and actual fetal weight.

\begin{tabular}{|l|c|c|}
\hline \multicolumn{1}{|c|}{ Parameters } & Pearson Correlation & P value \\
\hline FAST vs. EFW by Hadlock's formula (g) & $0.638^{* *}$ & 0.0001 \\
\hline FAST vs. Actual fetal weight (g) & $0.627^{* *}$ & 0.0001 \\
\hline $\begin{array}{l}\text { Actual fetal weight (g) vs. EFW by } \\
\text { Hadlock's formula (g) }\end{array}$ & $0.999^{* *}$ & 0.0001 \\
\hline
\end{tabular}

The AUC for the FAST as predictor of Birth weight $>4000 \mathrm{~g}$ was larger than that for it as predictor of birth weight $<2500$, indicating that FAST is a better predictor for Birth weight $>4000 \mathrm{~g}$ than for birth weight $<2500 \mathrm{~g}$ (Table 3).

Table (3): Validity of FAST as a predictor of birth weight $>4000 \mathrm{~g}$ and Birth Weight $<2500$

\begin{tabular}{|l|c|c|c|c|c|c|}
\hline Weight & AUC & $\begin{array}{c}\text { Best Cutoff } \\
\text { Value }\end{array}$ & Sensitivity & Specificity & PPV & NPV \\
\hline Birth weight $>\mathbf{4 0 0 0} \mathbf{g}$ & 0.88 & $\geq 7.3 \mathrm{~mm}$ & $91 \%$ & $80.0 \%$ & $64.3 \%$ & $82.0 \%$ \\
\hline Birth weight $<\mathbf{2 5 0 0} \mathbf{g}$ & 0.85 & $\leq 3.9 \mathrm{~mm}$ & $79.0 \%$ & $80.0 \%$ & $32.0 \%$ & $63.0 \%$ \\
\hline
\end{tabular}

Receiver operator characteristics (ROC) curve was constructed for FAST as predictor of Birth weight > 4000 g., as indicated by the significant large area under the curve (AUC) $[$ AUC $=0.820$,
$95 \%$ CI $(0.741$ to 0.802$), \quad \mathrm{p}<0.001]$ (Figure 1). The best cutoff value of FAST above which Birth weight > $4000 \mathrm{~g}$ is more likely was $7.2 \mathrm{~mm}$ [sensitivity $91 \%$, specificity $80 \%$, positive predictive value 
(PPV) $64.3 \%$, negative predictive value (NPV) $82 \%$. ROC curve was constructed for FAST as predictor of birth weight $<2500 \mathrm{~g}$, as indicated by the significant large AUC $[\mathrm{AUC}=0.751,95 \%$ CI $(0.325$

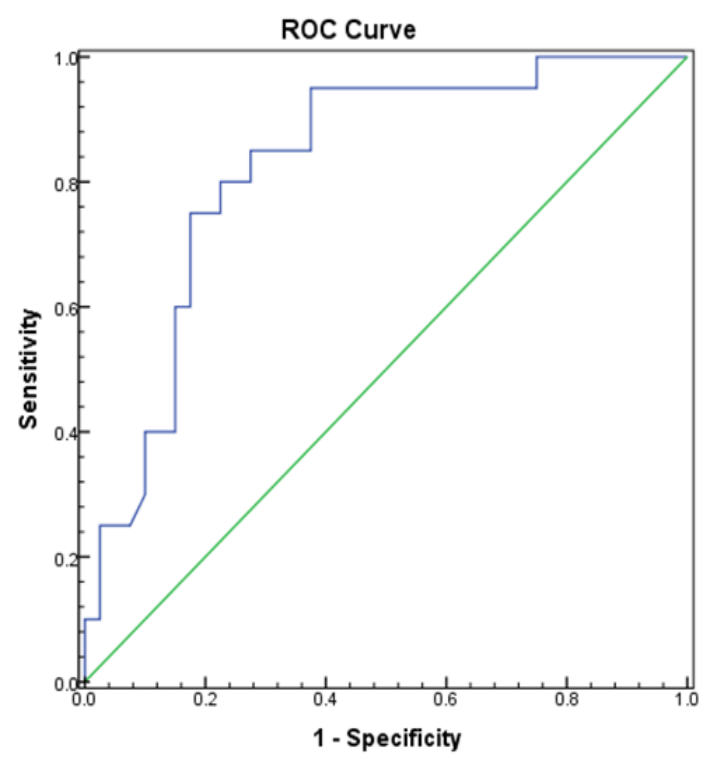

Figure (1): ROC Curve for FAST as Predictor of Birth weight > $4000 \mathrm{~g}$.

\section{DISCUSSION}

Among all included women, there were no significant correlation between fetal anterior abdominal wall fat thickness and each of maternal age, parity and gestational age. There was a significant positive correlation between fetal anterior abdominal wall fat thickness and birth weight.

There was a significant difference between women with different birth weight categories regarding the mean value of FAST, in such a way that the mean FAST was significantly higher in women who subsequently had neonates with Birth weight $>4000 \mathrm{~g}$ when compared to women who had average to 0.787$), p<0.05]$ (Figure 2). The best cutoff value of FAST below which low birth weight is more likely was $3.9 \mathrm{~mm}$ [sensitivity $79.0 \%$, specificity $80.0 \%$, PPV $32 \%$, NPV $63.0 \%$.

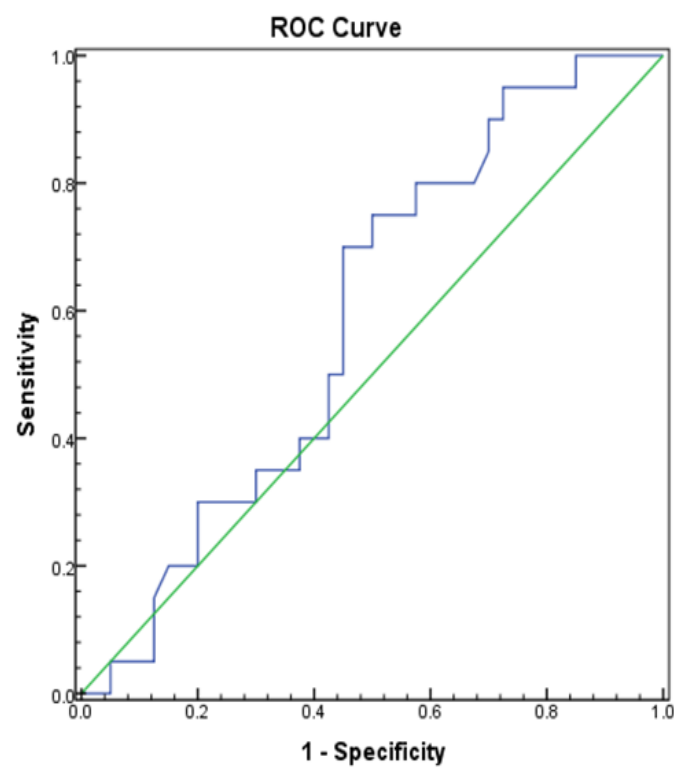

Figure (2): ROC Curve for FAST as Predictor of Low Birth Weight.

birth weights (2500-4000g) and in women who had neonates with average birth weights when compared to women who had neonates with birth weights $<2500 \mathrm{~g}$.

FAST was a significant predictor of Birth weight $>4000 \mathrm{~g}$, as indicated by the significant large area under the curve (AUC). The best cutoff value of FAST above which macrosomia was more likely was $7.3 \mathrm{~mm}$. FAST was a significant good predictor of birth weight $<2500$, as indicated by the significant large AUC. The best cutoff value of FAST below which low birth weight is more likely 3.9 $\mathrm{mm}$. The AUC for the FAST as predictor of birth weight $>4000 \mathrm{~g}$ was larger than that for it as predictor of low birth weight, 
indicating that FAST is a better predictor for macrosomia than for low birth weight.

EFW by Hadlock's Formula (BPD, FL, AC) had been evaluated during our study as being one of commonly used weight estimation formulas. At both birth weight extremities, it had lower sensitivity but higher specificity when compared to results obtained from FAST as a predictor of fetal weight.

In agreement with our study, Khalifa et al. (2019) concluded that FASTT showed a high statistically significant correlation with EFW by Hadlock formula and BW (birth weight). Also, a high statistically significant difference between each of the birth weight categories regarding the value of EFW by Hadlock formula as well as by FASTT was noted.

Both EFW and FASTT showed higher values in LGA category than AGA and SGA categories and also showed higher values in AGA category than SGA category Bhat et al. (2014) also agreed with our results, they plotted birth weight against FASTT (scatter plot graph), and it showed a positive significant correlation between FASTT and birth weight obtained by Pearson's correlation coefficient. Similarly, Grace and Josefina (2014) demonstrated that FASTT may be useful in the assessment of fetal nutritional risk as they showed a significant correlation between subcutaneous tissue thickness, estimated fetal weight, and actual BW.

Regarding the statistically significant difference of FASTT in different birth weight categories, Odthon et al. (2015) showed similar results. They studied the correlation between FASTT and birth weight. The mean FASTT differed significantly between normal and macrosomic fetuses.

Singh et al. (2014) stated that average subcutaneous tissue thickness in babies having a birth weight between 10th and 90th percentile was $5.4 \mathrm{~mm}$. below 10th percentile was $4.4 \mathrm{~mm}$, and above 90th percentile was $>5.9 \mathrm{~mm}$.

Additionally, the present study results were in accordance with the results recorded by Bhat et al. (2014), who found that the difference in mean FASTT between SGA, AGA and LGA babies was statistically significant. Regarding the demographic data of the included subjects, the current study showed no correlation between FASTT and any of the maternal age, gravidity, and parity. However, a statistically significant correlation was noted between the FASTT and gestational age calculated by date.

Results of Chen et al. (2014) and Farah et al. (2014) were in agreement with the current study. Both found that FASTT measurements increase as gestation advances. FASTT demonstrated higher sensitivity in LGA (90.9\%) than SGA $(86.9 \%)$ denoting that FASTT is a better indicator of LGA than SGA. The best cutoff value of FASTT for LGA was $9.2 \mathrm{~mm}$ and that of SGA was $4.5 \mathrm{~mm}$. Cutoff points of FASTT for LGA and SGA varied in different studies.

Despite that, Bhat et al. (2014) showed that FASTT was sensitive to predict large for gestational age (LGA) and not sensitive for SGA; a quite different cutoff value of FASTT for large babies was obtained $(6.25 \mathrm{~mm})$. Sensitivity for FASTT > $6.25 \mathrm{~mm}$ for large for gestational age babies was $79 \%$ and specificity is $70 \%$. They also stated that 
FASTT measurement for the prediction of small babies with birth weight $<2500 \mathrm{~g}$ was not sensitive.

Therefore, a cutoff value of FASTT for small for gestational age babies could not be obtained. Regarding SGA, the results of the current study were comparable to the results obtained by Khalifa et al. (2019) who found that the best cutoff value of the subcutaneous fat thickness for prediction of IUGR was $4.5 \mathrm{~mm}$, giving the sensitivity, specificity, positive predictive value, and negative predictive value of $76.0 \%, 75.3 \%, 47.5 \%$, and $91.4 \%$, respectively.

Close to our results was $W u$ et al. (2015) who found that fetuses with FASTT $\leq 4 \mathrm{~mm}$ were more likely to have low birth weight with a sensitivity of $90.0 \%(95 \%$ CI $=86.8-93.3)$ and a specificity of $53.5 \%$.

As FASTT showed statistical correlation with AC among the other fetal biometric parameters, comparing AC versus FASTT in cases of LGA was done. This was in conformity with Odthon et al. (2015) who evaluated the value of the sonographic measurement of fetal AC and FASTT for predicting fetal macrosomia. Compatible results were obtained, denoting that $\mathrm{AC}$ is better parameter for detection of LGA.

\section{CONCLUSION AND RECOMMENDATIONS}

FASTT is a good indicator of birth weight. It is a better parameter for LGA than SGA. It showed a high statistically significant correlation with $\mathrm{AC}$, yet it is less accurate than $\mathrm{AC}$ as an indicator of fetal macrosomia. FASTT is not affected by fetal gender and has no direct relation to the mode of delivery.

FAST can be combined with weight estimation formulas as a method to increase its accuracy especially at birth weight extremities.

However, a large study conducted on a wider scale of Egyptian population should be done in attempt to generate formulas for the estimation of fetal weight based on the Egyptian ethnic group and be the reference of medical practice in Egypt.

\section{REFERENCES}

1. Bajracharya J, Shrestha NS and Karki C (2013): Accuracy of prediction of birth weight by fetal ultrasound. Kathmandu Univ Med J., 10(2):74-6.

2. Bhat R, Nathan A, Ammar R, Vasudeva A, Adiga P, Bhat $P$ and Kumar $P$ (2014): Correlation of Fetal Abdominal Subcutaneous Tissue Thickness by Ultrasound to Predict Birth Weight. Journal of Clinical and Diagnostic Research, 8(4): 911.

3. Chen L, Wu J-J, Chen X-H, Cao L, Wu Y, Zhu L-J, Lv K-T, Ji C-B and Guo X-R (2014): Measurement of Fetal Abdominal and Subscapular Subcutaneous Tissue Thickness during Pregnancy to Predict Macrosomia: A Pilot Study. PLoS ONE 9(3): e93077.

4. Cunningham FG, Leveno KJ, Bloom SL, Spong YC, Dashe JS and Hoffman LB. (2014): William obstetrics. 24th ed. Pbl. Stamford: McGraw-Hill, Pp. 884-7.

5. Farah N, Stuart B and Harrold E (2010): Are there sex differences in Fetal Abdominal Subcutaneous Tissue (FAST) measurements? Eur J Obstet Gynecol., 148(2):118-120.

6. Grace DL and Josefina PK. (2012): Fetal abdominal subcutaneous tissue thickness (FASTT): correlation with other biometric measures and neonatal outcomes in a sample population of philipino fetuses. Philipp $\mathbf{J}$ Obstet Gynecol., 36(3):117-148. 
7. Khalifa E, Hassanein S and Eid H. (2019): Ultrasound measurement of fetal abdominal subcutaneous tissue thickness as a predictor of large versus small fetuses for gestational age. Egyptian Journal of Radiology and Nuclear Medicine, 50:80-82.

8. Kiserud T, Piaggio G, Carroli G, Widmer M, Carvalho J and Neerup JL (2017): The World Health Organization fetal growth charts: a multinational longitudinal study of ultrasound biometric measurements and estimated fetal weight. PLoS Med., 14:1002220.

9. Larkin JC, Hill LM, Speer PD and Simhan HN. (2012): Risk of morbid perinatal outcomes in small-for-gestational-age pregnancies: customized compared with conventional standards of fetal growth. Obstet Gynecol., 119: 21-27.

10. Odthon T, Pitukkijronnakorn $\mathrm{S}$, Chittacharoen A. (2015): Sonographic measurement fetal abdominal circumference and fetal abdominal subcutaneous tissue thickness for predicting fetal macrosomia. J Obstet Gynaecol., 5:216-222.

11. Singh A, Chander R, Kumari S (2014): Estimation of fetal weight and its correlation with actual birth weight by sonographic measurement of fetal abdominal subcutaneous tissue thickness. J Evol Med Dent Sci 3(37):9610-9621.

12. Spellacy WN, Miller S, Winegar A, Peterson PQ and Odthon T. (2015): Fetal Abdominal Circumference and Fetal Abdominal 221 Subcutaneous Tissue Thicknesses for Predicting Fetal Macrosomia. Macrosomia-maternal Characteristics and Infant, 23: 4-9.

13. Wu M, Shao G, Zhang F (2015): Estimation of fetal weight by ultrasonic examination. Int J Clin Exp Med 8(1):540 


\section{قياس سمك النسيج البطنى تحت الجلا باستخدام الأشعة التليفزيونية لجنين مكتمل النمو في التنبوء بوزن الطقل عند الولادة يسرى عون، محمد جبريل، ساجد المظالى لئل} قسم النساء والتوليد، كلية الطب، جامعة الأزهر، القاهرة

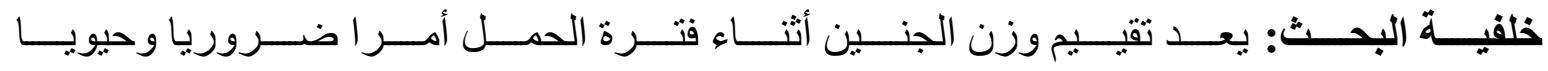

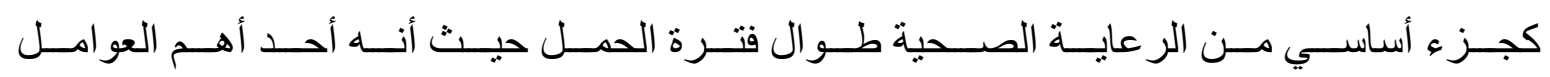

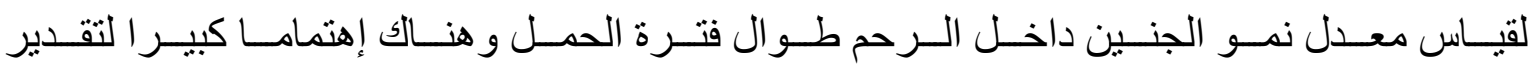

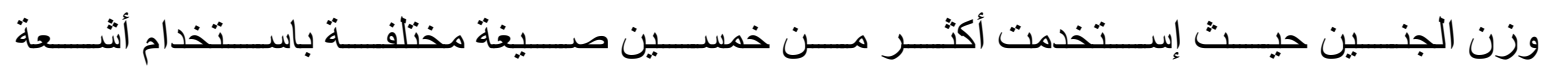
الموجات فوق الصوتية لتحديد وزن الجنين عند الولادة.

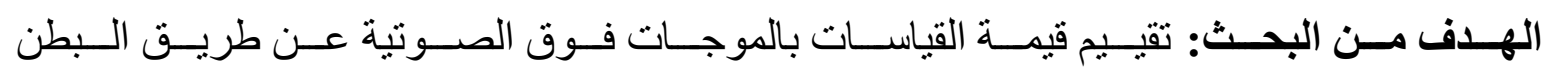

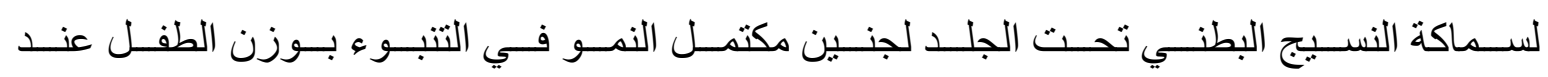
الو لادة.

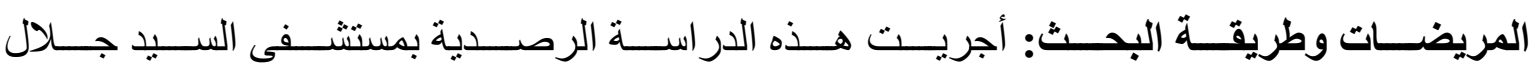

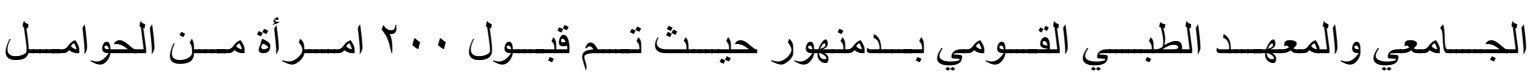

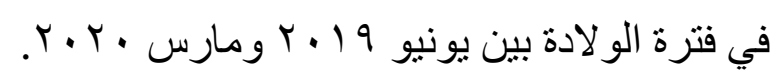

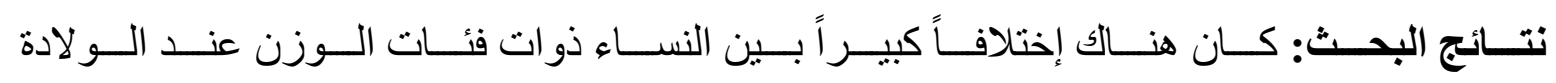

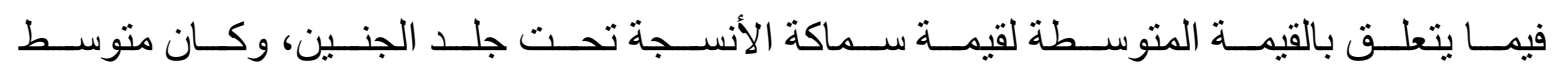

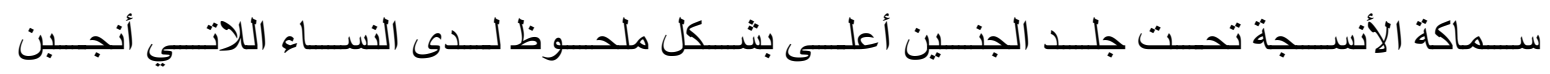

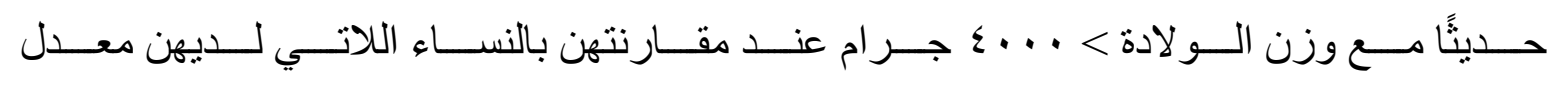

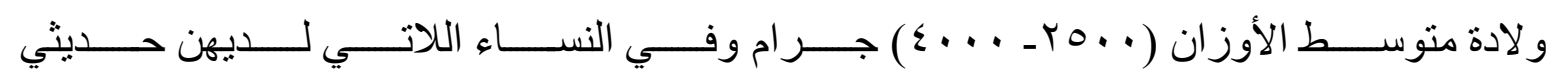

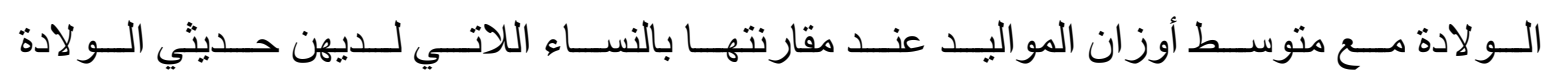

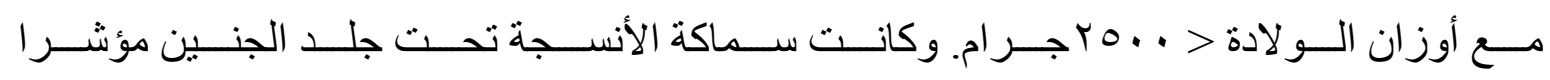

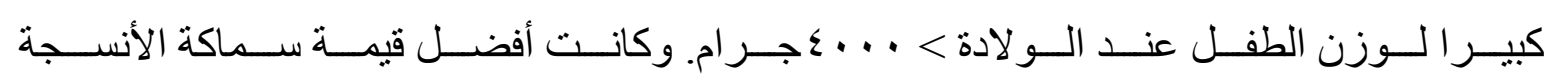

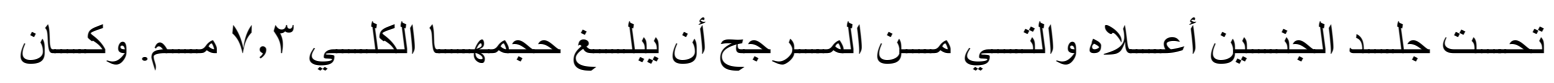

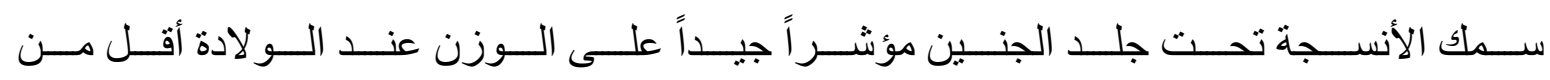

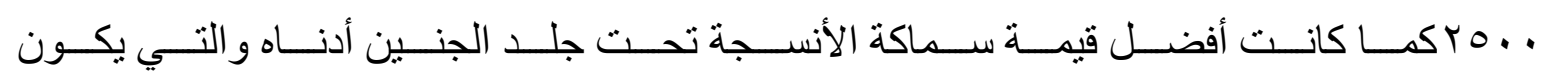




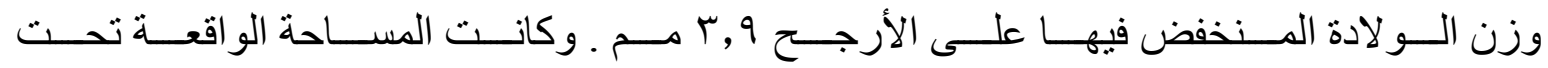

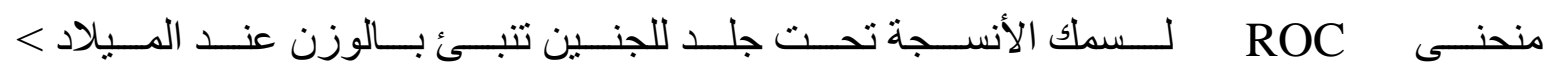

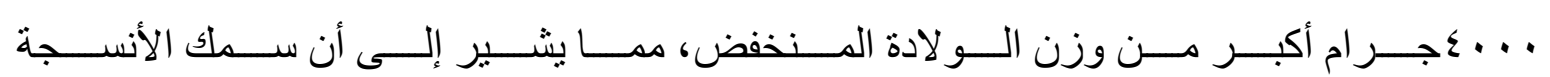

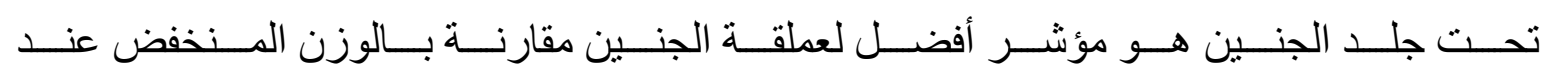
الو لادة.

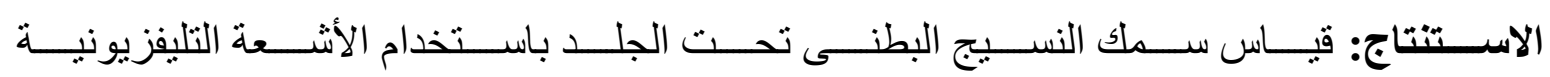
مفيد فى التنبوء بوزن الطفل و عملقة الجنين. 